\title{
First record of the North American invasive crayfish Pacifastacus leniusculus from the Kanto region, Tone River basin, central Japan: a range expansion to a warm water area
}

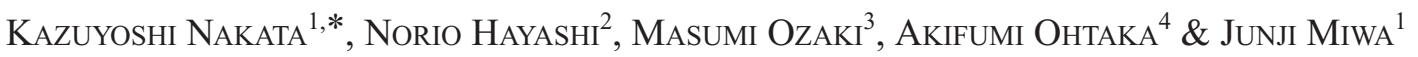 \\ ${ }^{1}$ River Restoration Research Team, Water Environment Research Group, Public Works Research Institute, 1-6 Minami-Hara, Tsukuba, Ibaraki \\ 305-8516, Japan \\ ${ }^{2}$ Natural History Museum and Institute, Chiba, 955-2 Aoba-cho, Chuo-ku, Chiba, Chiba 260-8682, Japan \\ ${ }^{3}$ Chiba Biodiversity Center, Nature Conservation Division, Environmental and Community Affairs Department, Chiba Prefectural Government, \\ 955-2 Aoba-cho, Chuo-ku, Chiba, Chiba 260-8682, Japan \\ ${ }^{4}$ Department of Natural Science, Faculty of Education, Hirosaki University, 1 Bunkyo-cho, Hirosaki, Aomori 036-8560, Japan
}

Received 11 February 2010; Accepted 7 May 2010

\begin{abstract}
The North American invasive signal crayfish Pacifastacus leniusculus was designated as an 'Invasive Alien Species' by the Ministry of the Environment of Japan and by the Ministry of Agriculture, Forestry and Fisheries of Japan on 1 February 2006. We report the first record of P. leniusculus from the Kanto region (Chiba Prefecture), central Japan. Adult specimens of $P$. leniusculus were collected from the Tone River basin between September 2009 and January 2010. Ectosymbiotic crayfish worms (Annelida, Clitellata, Branchiobdellidae) were found on the crayfish and all specimens were identified as Sathodrilus attenuatus, which outside of its home range in North America occurs only in the Hokkaido and Fukushima Prefecture populations of $P$. leniusculus; thus suggesting that $P$. leniusculus in the Tone River basin was introduced from Hokkaido or Fukushima Prefecture. Signal crayfish is considered a cool water species and has been reported mostly in Hokkaido, northern Japan, but our findings strongly indicate that P. leniusculus has become established in a warm water area in central Japan, where the maximum water temperature is above $30^{\circ} \mathrm{C}$ in summer. These results indicate that $P$. leniusculus can inhabit warm water areas as well as cool areas and would be able to extend its distribution over a wide range in Japan.
\end{abstract}

Key words: Branchiobdellida, invasive alien species, Pacifastacus leniusculus, Sathodrilus attenuatus, signal crayfish

The North American signal crayfish Pacifastacus leniusculus (Dana) is recognized as an invasive species that has a strong negative influence on native animals, especially on native crayfish (e.g. Holdich 1999, Nyström 1999). In Europe, North American invasive crayfish species, including P. leniusculus, have eradicated many populations of native crayfish mainly by transmission of the crayfish plague fungus Aphanomyces astaci Schikora, which is lethal to European crayfish, but not to North American crayfish species (e.g. Holdich 1999).

Pacifastacus leniusculus was first introduced into Japan from northwestern North America for use as food in 1928 (Kawai et al. 2002b). At first, the distribution of P. leniusculus in Japan was restricted to Lake Mashu, eastern Hokkaido, and Tankai Reservoir, Shiga Prefecture. However, P. leniusculus has now been established in many rivers and lakes, especially in eastern Hokkaido, northern Japan (Usio et al. 2007). In Hokkaido, P. leniusculus has displaced the endangered Japan-

*Corresponding author: Kazuyoshi Nakata; E-mail, nakata55@pwri.go.jp ese native crayfish Cambaroides japonicus (De Haan) in many lakes and rivers (e.g. Kawai et al. 2002a). This replacement can be caused through interspecific competition for shelter (Usio et al. 2001, Nakata \& Goshima 2003) and by direct predation on $C$. japonicus, mainly by large specimens of P. leniusculus (Nakata \& Goshima 2006). In addition, P. leniusculus can have a strong impact on aquatic food webs, since it exerts a greater effect than native crayfish on the other biota, such as benthic fish, mollusks and macrophytes (Holdich 1999, Nyström 1999). Consequently, P. leniusculus was designated as an 'Invasive Alien Species' (IAS) by the Ministry of the Environment of Japan and by the Ministry of Agriculture, Forestry and Fisheries of Japan on 1 February 2006. The IAS Act prohibits the raising, importing, transferring and releasing of IAS in Japan. Since 2006, control of P. leniusculus has been conducted in Hokkaido under the IAS Act (Usio et al. 2007).

Generally, P. leniusculus is considered a cool water species (e.g. Henttonen \& Huner 1999). In Hokkaido, many of the established habitats of P. leniusculus are frozen in winter (e.g. Nakata et al. 2004). On the other hand, Nakata et al. (2005) 


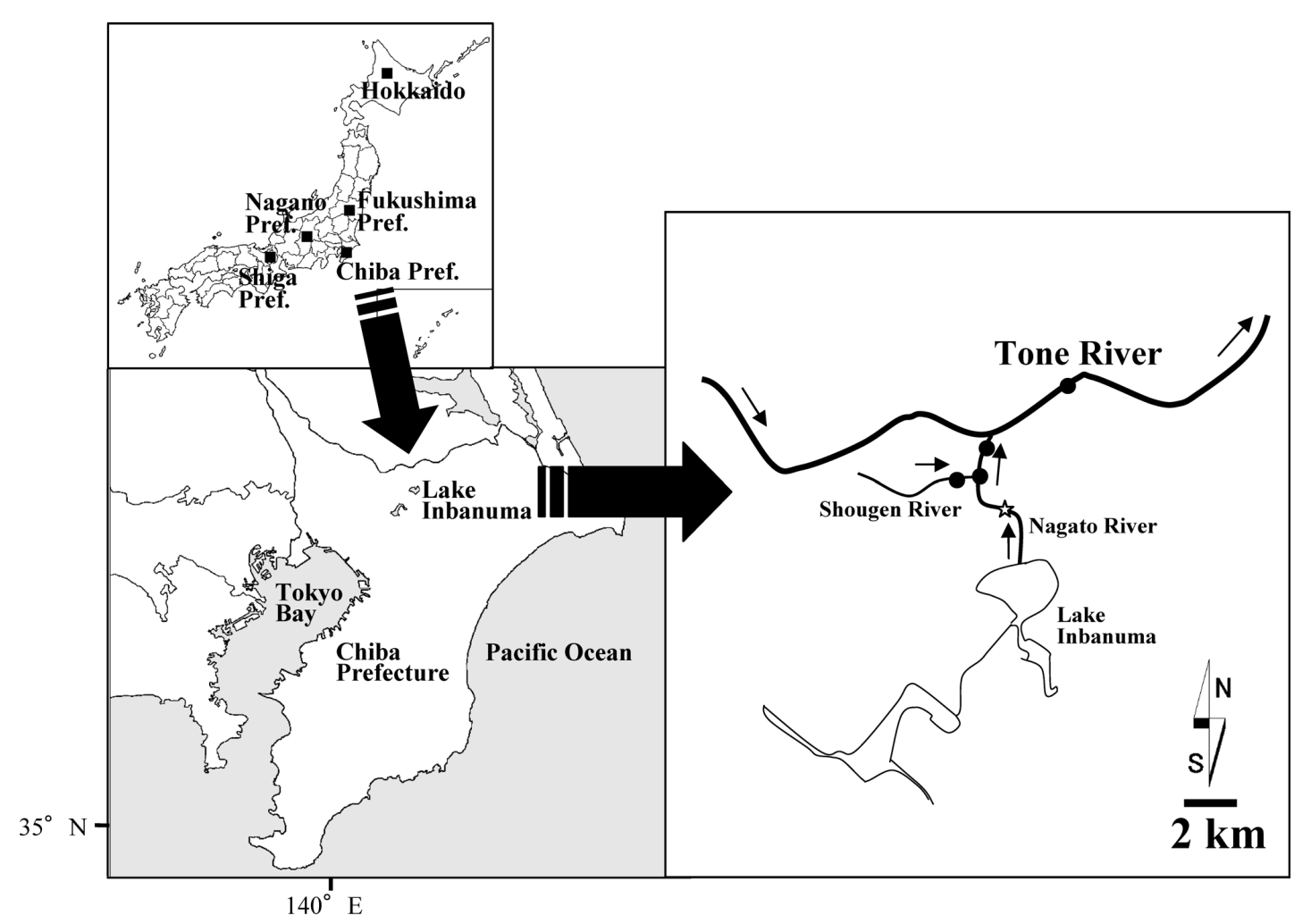

Fig. 1. Map showing the study sites in the Tone River basin in Chiba Prefecture, central Japan. Solid squares show localities (as of 2009) of the invasive signal crayfish Pacifastacus leniusculus in Japan; lakes and rivers in Hokkaido, lakes in the Bandai-Asahi National Park in Fukushima Prefecture, Tankai Reservoir in Shiga Prefecture, an irrigation stream in Akashina in Nagano Prefecture and the new locality in Chiba Prefecture. Solid circles show where P. leniusculus were collected during this study. The open star shows where water temperatures were measured by using a data logger (see text and Fig. 3). Arrows along the rivers show the direction of river flow.

found that $P$. leniusculus coexists with another North American invasive crayfish Procambarus clarkii (Girard), which is known as a warm water species (e.g. Henttonen \& Huner 1999), in a small river in Hokkaido, of which a hot spring forms the source and where the maximum water temperature reaches above $25^{\circ} \mathrm{C}$. In addition, a temperature tolerance test suggested that $P$. leniusculus can survive up to approximately $30^{\circ} \mathrm{C}$ (Nakata et al. 2002). From these findings, Nakata et al. (2005) concluded that $P$. leniusculus might be able to extend its distribution over a wide range in Japan, if it was released there, although the distribution areas at that time were mainly restricted to Hokkaido (Kawai et al. 2002a, Ohtaka et al. 2005). Actually, P. leniusculus has so far been found in three prefectures (Fukushima, Nagano and Shiga prefectures) in Honshu, south of Hokkaido (Usio et al. 2007), but these habitats in Honshu are located at high altitudes (797, 510 and 470 $\mathrm{m}$ in Fukushima, Nagano and Shiga prefectures, respectively) and thus in relatively cold climates. However, we recently found a new invasion of $P$. leniusculus in a warm water area in the Kanto region (Chiba Prefecture), central Japan, which is located at a low altitude (about $11 \mathrm{~m}$ ). In this paper, we report the first record of $P$. leniusculus from a warm water area in the Kanto region.

On 29 September 2009, a local fisherman reported to us the capture of an unusual crayfish in the Tone River basin (the Nagato River) (Fig. 1). This crayfish specimen was identified as $P$. leniusculus. In this study, we were able to obtain 12 specimens ( 6 males and 6 females) of $P$. leniusculus collected by the authors and local fishermen from the Tone River basin (the Tone River, Nagato River and Shougen River) between September 2009 and January 2010 (now housed in the Natural History Museum and Institute, Chiba) (Figs. 1, 2). These specimens were collected in shallow waters along the banks of the rivers by using cage traps $(84.5 \mathrm{~cm} \times 56 \mathrm{~cm} \times 30 \mathrm{~cm}, 1 \times w \times h$, $12-\mathrm{mm} \mathrm{mesh}$ ) or fishing nets with various sizes and then were fixed in $10 \%$ formalin or $99 \%$ ethanol. The total length (TL) from the apex of the rostrum to the caudal margin of the telson and the carapace length (CL) from the posterior margin of the orbit to the mid-dorsal posterior margin of the carapace in the 12 specimens were $119.9 \pm 3.6 \mathrm{~mm}$ and $46.7 \pm 1.8 \mathrm{~mm}$ (mean \pm standard error), respectively. The body sizes of the 12 specimens ranged $96.9-137.3 \mathrm{~mm}$ in TL and $35.5-56.3 \mathrm{~mm}$ in CL.

The presence or absence and the species of ectosymbiotic crayfish worms (Annelida, Clitellata, Branchiobdellidae) can be used as a method for tracing the spread of $P$. leniusculus around Japan, since different species compositions of crayfish worms have been found in different populations of $P$. leniusculus in Japan (Ohtaka et al. 2005). We examined the 12 speci- 


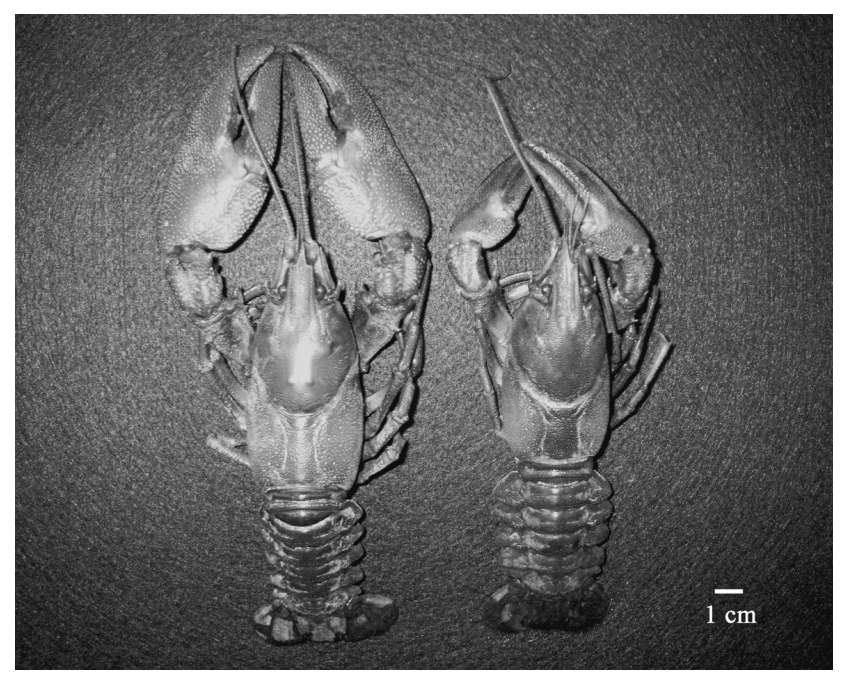

Fig. 2. Adult male (left) and female (right) of Pacifastacus leniusculus collected from the Nagato River in the Tone River basin on 15 December 2009.

mens of $P$. leniusculus from the Tone River basin for branchiobdellidans, based on the method by Ohtaka et al. (2005). Many branchiobdellidans (581 worms in total) were retained on the surface of every host after fixation, and all specimens were identified as Sathodrilus attenuatus Holt. This species has so far been reported only from the Hokkaido and Fukushima Prefecture populations among invasive populations of P. leniusculus throughout the world (Kawai et al. 2004, Ohtaka et al. 2005); the population of P. leniusculus in Fukushima is considered to originate from the populations of Hokkaido (Kawai et al. 2004). Moreover, entocytherid ostracods were collected from the 12 specimens of $P$. leniusculus from the Tone River basin and the species was Uncinocythere occidentalis (Kozloff \& Whitman), which is commensal on $P$. leniusculus in Hokkaido (Smith \& Kamiya 2001). From these findings, it is highly probable that P. leniusculus in the Tone River basin was introduced from Hokkaido or Fukushima Prefecture.

Kawai et al. (2004) reported that the mean rostral acumen ratio (length/width) can be used as a useful tool for tracing the spread of P. leniusculus in Japan, and the ratios on average are 1.14 in Hokkaido and Fukushima Prefecture and 1.05 in Shiga Prefecture. The mean value of length/width ratio of the rostral acumen in the Tone River basin specimens was 1.12 \pm 0.03 ( \pm standard error), which is similar in the Hokkaido and Fukushima Prefecture populations (Kawai et al. 2004). This result also suggests that P. leniusculus in the Tone River basin was introduced from Hokkaido or Fukushima Prefecture.

In general, temperature is a major limiting factor for aquatic poikilothermic animals, as temperature influences the geographic and local distribution, growth, metabolism, reproduction and life histories, and has indirect effects through its influence on water chemistry (Lee \& Wickins 1992). Maximum water temperature can be a major limiting factor to predict possible distribution ranges of invasive P. leniusculus (Nakata

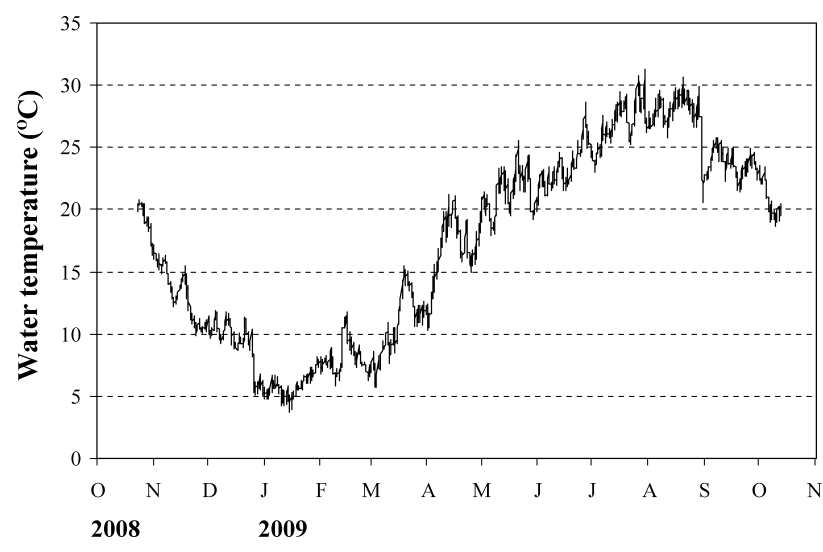

Fig. 3. Seasonal fluctuations of water temperature in the Nagato River between 23 October 2008 and 14 October 2009.

et al. 2002). The Kanto region, including Chiba Prefecture, is a considerably warmer area than Hokkaido, where P. leniusculus has become established in many lakes and rivers (Usio et al. 2007). To examine the relationship between the possibility of establishment of invasive $P$. leniusculus and high water temperature, we obtained data of water temperatures in the Nagato River (Fig. 1), which were continuously recorded at 60-min intervals by a data logger (Hobo Pendant Temperature Logger UA-001-64; Onset Computer Cooperation, USA) at a depth of approximately $30 \mathrm{~cm}$ along the bank of the river from 23 October 2008 to 14 October 2009. The data of the water temperatures were provided by the Chiba Prefectural Fisheries Research Center Fresh-water Station, Japan.

In most of the established habitats of $P$. leniusculus in Hokkaido, the water temperature increases in summer up to only about $20^{\circ} \mathrm{C}$ (e.g. Nakata et al. 2004). In contrast, in the Nagato River, the maximum water temperature was $31.3^{\circ} \mathrm{C}$ on 30 July 2009, and the water temperature was above $25^{\circ} \mathrm{C}$ every day during July and August (Fig. 3). According to local fishermen, $P$. leniusculus, including ovigerous females, have been observed in the Tone River basin from 2005 onward. Furthermore, 12 adult specimens of $P$. leniusculus were collected in this study. Hence, it is highly probable that $P$. leniusculus has become established and may reproduce in the Tone River basin. This strongly indicates that $P$. leniusculus can inhabit warm water areas, where the water temperature reaches above $30^{\circ} \mathrm{C}$ in summer; this is supported by a temperature tolerance test that suggested that the ultimate upper lethal temperature (50\% mortality) of P. leniusculus is $31.1^{\circ} \mathrm{C}$ (Nakata et al. 2002). The invasive $P$. leniusculus is considered as a cool water species, but it would be able to extend its distribution over a wide range in Japan, if $P$. leniusculus were released there.

\section{Acknowledgements}

We thank Dr. R. J. Smith of the Lake Biwa Museum, Japan, for identifying the ostracod specimens, and Messrs. K. Kawazu and H. Sakamoto of the Chiba Prefectural Fisheries Research Center Fresh-water Station, Japan, for providing use- 
ful information and the data of water temperature in the $\mathrm{Na}$ gato River. We also thank Ms. H. Matsuda of Hiroshima University, Japan, for providing literature. Special thanks are due to local fishermen for providing information on the signal crayfish in the Tone River basin, as well as for providing specimens thereof. We appreciate the anonymous reviewers for their valuable comments on the manuscript.

\section{References}

Henttonen P, Huner JV (1999) The introduction of alien species of crayfish in Europe: a historical introduction. In: Crayfish in Europe as Alien Species (eds Gherardi F, Holdich DM). Crust Issues 11, A. A. Balkema, Rotterdam, pp. 13-22.

Holdich DM (1999) The negative effects of established crayfish introductions. In: Crayfish in Europe as Alien Species (eds Gherardi F, Holdich DM). Crust Issues 11, A. A. Balkema, Rotterdam, pp. 31-47.

Kawai T, Mitamura T, Ohtaka A (2004) The taxonomic status of the introduced North American signal crayfish, Pacifastacus leniusculus (Dana, 1852 ) in Japan, and the source of specimens in the newly reported population in Fukushima Prefecture. Crustaceana 77: 861-870.

Kawai T, Nakata K, Hamano T (2002a) Temporal changes of the density for two crayfish species, the native Cambaroides japonicus (De Haan) and the alien Pacifastacus leniusculus (Dana), in natural habitats of Hokkaido, Japan. Freshw Crayfish 13: 198-206.

Kawai T, Nakata K, Kobayashi Y (2002b) A study of the taxonomic status and introduction of two Pacifastacus crayfish species from North America to Japan. J Nat Hist Aomori 7: 59-71. (in Japanese with English abstract)

Lee DO'C, Wickins JF (1992) Crustacean Farming. Blackwell Scientific, Oxford, $392 \mathrm{pp}$.

Nakata K, Goshima S (2003) Competition for shelter of preferred sizes between the native crayfish species Cambaroides japonicus and the alien crayfish species Pacifastacus leniusculus in Japan in relation to prior residence, sex difference, and body size. J Crust Biol 23: 897-907.

Nakata K, Goshima S (2006) Asymmetry in mutual predation between the endangered Japanese native crayfish Cambaroides japonicus and the North American invasive crayfish Pacifastacus leniusculus: a possible reason for species replacement. J Crust Biol 26: 134-140.

Nakata K, Hamano T, Hayashi K, Kawai T (2002) Lethal limits of high temperature for two crayfishes, the native species Cambaroides japonicus and the alien species Pacifastacus leniusculus in Japan. Fish Sci 68: $763-767$.

Nakata K, Tanaka A, Goshima S (2004) Reproduction of the alien crayfish species Pacifastacus leniusculus in Lake Shikaribetsu, Hokkaido, Japan. J Crust Biol 24: 496-501.

Nakata K, Tsutsumi K, Kawai T, Goshima S (2005) Coexistence of two North American invasive crayfish species, Pacifastacus leniusculus (Dana, 1852) and Procambarus clarkii (Girard, 1852) in Japan. Crustaceana 78: 1389-1394.

Nyström P (1999) Ecological impact of introduced and native crayfish on freshwater communities: European perspectives. In: Crayfish in Europe as Alien Species (eds Gherardi F, Holdich DM). Crust Issues 11, A. A. Balkema, Rotterdam, pp. 63-85.

Ohtaka A, Gelder SR, Kawai T, Saito K, Nakata K, Nishino M (2005) New records and distributions of two North American branchiobdellidan species (Annelida: Clitellata) from introduced signal crayfish, Pacifastacus leniusculus, in Japan. Biol Invasions 7: 149-156.

Smith RJ, Kamiya T (2001) The first record of an entocytherid ostracod (Crustacea: Cytheroidea) from Japan. Benthos Res 56: 57-61.

Usio N, Konishi M, Nakano S (2001) Species displacement between an introduced and a "vulnerable" crayfish: the role of aggressive interactions and shelter competition. Biol Invasions 3: 179-185.

Usio N, Nakata K, Kawai T, Kitano S (2007) Distribution and control status of the invasive signal crayfish (Pacifastacus leniusculus) in Japan. Jpn J Limnol 68: 471-482. (in Japanese with English abstract) 